\title{
6 Minute Walk Functional Test
}

National Cancer Institute

\section{Source}

National Cancer Institute. 6 Minute Walk Functional Test. NCI Thesaurus. Code C115789.

A standardized rating scale developed by Bruno Blake in 1963, which is a performancebased evaluation of functional exercise capacity in subjects with chronic respiratory disease and heart failure, as well as other populations such as healthy older adults and people suffering from fibromyalgia and scleroderma. This functional test contains 6 items and measures the distance an individual is able to walk over a total of six minutes on a hard, flat surface. 